\title{
ORIGINAL ARTICLE \\ Nutritional impact of adding a serving of mushrooms to USDA Food Patterns - a dietary modeling analysis
}

\author{
Sanjiv Agarwal ${ }^{*}$ and Victor L. Fulgoni, III² \\ 'NutriScience LLC, East Norriton, PA, USA; ${ }^{2}$ Nutrition Impact, LLC, Battle Creek, MI, USA
}

Popular scientific summary

- Mushrooms are fungi but are counted as vegetables and are an important source of nutrients and bioactive compounds.

- The objective was to assess the nutritional impact of adding a serving of mushrooms in USDA Food Patterns.

- Addition of mushrooms to USDA Food Patterns (US-style, Mediterranean-style, and Vegetarian) increased several micronutrients including shortfall nutrients, and had a minimal or no impact on overall calories, sodium or saturated fat.

\section{Abstract}

Mushrooms are part of vegetables and are important source of nutrients and bioactive compounds. The objective was to assess the nutritional impact of adding a serving of mushrooms in USDA Food Patterns using a similar approach to that used by USDA for Dietary Guidelines.

A composite of commonly consumed raw mushrooms (white, brown/crimini and portabella; at 1:1:1 ratio) and raw speciality mushrooms (oyster mushrooms) were used for modeling. The United States Department of Agriculture (USDA) Food Data central database (https://fdc.nal.usda.gov/) was used to obtain nutrient profiles of mushrooms. Nutritional profiles of USDAs Food Patterns were obtained from the Scientific Report of the 2015 Dietary Guidelines Advisory Committee, Appendix E-3 (https://health.gov/dietaryguidelines/2015-scientific-report/15-appendix-E3/) and dietary modeling was accomplished by adding nutrients from mushrooms.

Addition of an $84 \mathrm{~g}$ serving of commonly consumed raw mushrooms to USDA Food Patterns resulted in about $1 \%$ increase in calories, less than $5 \%$ increase in macronutrients, $2-3 \%$ increase in fiber, $8-12 \%$ increase in potassium, $12-18 \%$ increase in riboflavin, $11-26 \%$ increase in niacin, $11-23 \%$ selenium and $16-26 \%$ increase in copper depending upon the pattern type and calorie level. Mushrooms exposed to UV light to increase vitamin D levels to 200 IU/serving also increased vitamin D by $67-90 \%$ in USDA Food Patterns. Addition of oyster mushroom also additionally increased 8-11\% vitamin D and 10-16\% choline in USDA Food Patterns. Addition of mushrooms had minimal effect on sodium ( $1 \%$ or less increase) and no effect on saturated fat or cholesterol in USDA Food Patterns. Based on published data, a serving of commonly consumed mushrooms would also be expected to add $2.2 \mathrm{mg}$ ergothioneine and $3.5 \mathrm{mg}$ glutathione to the USDA Food Patterns.

Addition of mushrooms to USDA Food Patterns increased several micronutrients including shortfall nutrients (such as potassium, vitamin D and choline), and had a minimal or no impact on overall calories, sodium or saturated fat.

Keywords: healthy US-style food pattern; healthy Mediterranean-style pattern; healthy vegetarian pattern; white mushrooms; crimini mushrooms; portabella mushrooms; oyster mushrooms

Received: 2 October 2020; Revised: 4 January 2021; Accepted: 5 January 2021; Published: 5 February 2021

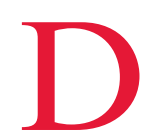
ietary guidelines around the world unequivocally recommend a balanced diet with adequate intake (AI) of essential nutrients across the lifespan. 2015-2020 Dietary Guidelines for Americans (DGA) recommend following a healthy eating pattern and choose a variety of nutrient dense foods, while limiting intake of added sugar, saturated fat and sodium (1). USDA Food Patterns were developed and released as part of DGA. 
They include the characteristics of healthy eating patterns with details on how to follow the DGA guidance within caloric needs, and can be used to plan and serve meals for individuals, households and communities. Three USDA Food Patterns were developed for DGA: 1) healthy USstyle food pattern (HUP) provides details on each of the food groups and other dietary components of public health importance and is based on nutrient dense types and proportions of foods typically consumed in the US; 2) healthy Mediterranean-style pattern (HMP) adapted from the HUP by modifying amounts from some food groups to more closely reflect Mediterranean-style diets associated with positive health outcomes in studies, and 3) healthy vegetarian pattern (HVP) adapted from the HUP, modifying amounts from some food groups (such as protein foods) to more closely reflect eating patterns of vegetarians (2).

Mushrooms have long been a part of the human diet and used as both foods and medicine $(3,4)$. They are the fruiting bodies of filamentous fungi that grow above the ground $(4,5)$. From a culinary standpoint, they are considered as vegetables and have been informally categorized among the 'white vegetables' (6). The USDA's MyPlate (ChooseMyPlate.gov) (7) considers mushrooms as part of other vegetables and $1 / 2$ cup of mushrooms counts as $1 / 2$ cup-equivalent in the vegetable group (other vegetables subgroup). Mushrooms are low fat, low calorie foods and can be an important source of nutrients and bioactive compounds. Mushrooms generally provide many B-vitamins, selenium, copper, potassium and fiber $(4,8)$. They can also be an abundant source of vitamin D when exposed to UV light (9). Mushrooms also contain a variety of phenolic antioxidants as secondary metabolites; however the health significance of these compounds requires further research (10). Using National Health and Nutrition Examination Survey (NHANES) 2001-2010 data, we earlier reported that mushroom intake was associated with higher intakes of several key nutrients and better diet quality, however their intake was low at $2.3 \mathrm{~g}$ per day per capita or $20.6 \mathrm{~g}$ per day among consumers (11).

The objective of the current study was to assess the nutritional impact of adding a serving of mushrooms in USDA food patterns (HUP, HMP, HVP) using food pattern modeling.

\section{Methods}

To achieve the objective of this study, we created the following composites of raw mushrooms:

1. Commonly consumed mushrooms: white + crimini + portabella at 1:1:1 ratio.

2. ' 1 ' above exposed to UV light to increase vitamin D to $200 \mathrm{IU} /$ serving.

3. Specialty mushrooms: oyster mushrooms.
Nutrient profiles of mushrooms used were obtained from USDA Food Data Central database (12) using the specific foods codes for each specific mushroom: white (mushroom, white, raw; FDC ID 169251), crimini (mushroom, brown, Italian or crimini, raw; FDC ID 168434), portabella (mushroom, portabella, raw; FDC ID 169255), and oyster (mushroom, oyster, raw; FDC ID 168580). Nutrient profiles for each mushroom composite were then computed for $84 \mathrm{~g}$ or $1 / 2$ cup equivalent serving (Table 1 ).

Nutrient profiles of USDA Food Patterns: HUP, HMP, and HVP were obtained from publicly available datafiles (2). We selected three calorie levels 1,600, 2,000 and 2,400 kcal per day as this range is appropriate for most adolescents (9-18 years) adults (19+ years) (2).

Table 1. Nutrient profiles of mushrooms composites (per $84 \mathrm{~g}$ serving) (12)

\begin{tabular}{|c|c|c|}
\hline Variables & $\begin{array}{l}\text { Commonly consumed } \\
\text { mushrooms (white }+ \\
\text { crimini + portabella } \\
\text { mushrooms at I:I:I ratio) }\end{array}$ & $\begin{array}{c}\text { Oyster } \\
\text { mushrooms }\end{array}$ \\
\hline Energy (kcal) & 18.5 & 27.7 \\
\hline Protein $(\mathrm{g})$ & 2.16 & 2.78 \\
\hline Carbohydrate (g) & 3.20 & 5.12 \\
\hline Dietary fiber (g) & 0.81 & 1.93 \\
\hline Total fat (g) & 0.22 & 0.34 \\
\hline Saturated fat (g) & 0.02 & 0.05 \\
\hline Cholesterol (mg) & 0.00 & 0.00 \\
\hline Calcium (mg) & 6.72 & 2.52 \\
\hline Copper (mg) & 0.31 & 0.20 \\
\hline Iron (mg) & 0.34 & 1.12 \\
\hline Manganese (mg) & 0.07 & 0.09 \\
\hline Phosphorus (mg) & 87.9 & 101 \\
\hline Potassium (mg) & 316 & 353 \\
\hline Selenium $(\mu \mathrm{g})$ & 15.1 & 2.18 \\
\hline Sodium (mg) & 5.6 & 15.1 \\
\hline Zinc (mg) & 0.60 & 0.65 \\
\hline Vitamin A, RAE ( $\mu \mathrm{g})$ & 0 & 1.68 \\
\hline Thiamin (mg) & 0.07 & 0.105 \\
\hline Riboflavin (mg) & 0.29 & 0.29 \\
\hline Niacin (mg) & 3.33 & 4.16 \\
\hline Folate, DFE $(\mu \mathrm{g})$ & 19.6 & 31.9 \\
\hline Vitamin $B_{6}(m g)$ & 0.10 & 0.09 \\
\hline Vitamin $B_{12}(\mu g)$ & 0.05 & 0 \\
\hline Vitamin C (mg) & 0.59 & 0 \\
\hline Vitamin D (IU) & 5.6 & 24.4 \\
\hline Vitamin E (mg) & 0.01 & 0 \\
\hline Choline (mg) & 17.0 & 40.9 \\
\hline
\end{tabular}

Mushroom specific USDA Food Codes used were: white mushroom - FDC ID 16925I; crimini mushroom - FDC ID I68434); portabella mushroom - FDC ID 169255 and oyster mushroom - FDC ID I68580. Vitamin D values for the mushrooms exposed to UV light was $200 \mathrm{IU}$. RAE, retinol activity equivalents; DFE, dietary folate equivalents; IU, international units. 
Dietary modeling was accomplished by adding nutrients from each mushroom composite to the USDA Food Patterns (HUP, HMP and HVP) and modified nutrient profiles were created using Microsoft Excel (Version 2016, Microsoft, Inc.).

\section{Results}

Addition of an $84 \mathrm{~g}$ serving of commonly-consumed raw mushrooms to 2,000 kcal HUP resulted in $0.92 \%$ increase in calories, less than 3\% increase in macronutrients, $2.62 \%$ increase in fiber, $22.1 \%$ increase in copper, $9.45 \%$ increase in potassium, $13.7 \%$ increase in selenium, $13.6 \%$ increase in riboflavin and $13.9 \%$ increase in niacin, and had no effect (less than $1 \%$ increase) on sodium, saturated fat or cholesterol (Table 2). Mushrooms contain very little sodium $(<6 \mathrm{mg})$ or saturated fat $(0.02 \mathrm{~g})$ and are cholesterol free (Table 1). Addition of an $84 \mathrm{~g}$ serving of commonly consumed raw mushrooms to 2,000 kcal HMP resulted in $0.92 \%$ increase in calories, less than $3 \%$ increase in macronutrients, $2.62 \%$ increase in fiber, $21.2 \%$ increase in copper, $9.44 \%$ increase in potassium, $12.8 \%$ increase in selenium, $15.1 \%$ increase in riboflavin and $13.3 \%$ increase in niacin, and had no effect (less than $1 \%$ increase) on sodium, saturated fat or cholesterol (Table 3). Addition of an $84 \mathrm{~g}$ serving of commonly consumed raw mushrooms to 2,000 kcal HVP resulted in $0.92 \%$ increase in calories, $3 \%$ or less increase in macronutrients, $2.32 \%$ increase in fiber, $19.3 \%$ increase in copper, $9.56 \%$ increase in potassium, $19.9 \%$ increase in selenium, $14.3 \%$ increase in riboflavin and 20.8\% increase in niacin, and had no effect (less than $1 \%$ increase) on sodium, saturated fat or cholesterol (Table 4). Almost similar changes were also noted with addition of an $84 \mathrm{~g}$ serving of commonly-consumed mushrooms to 1,600 and 2,400 kcal versions of HUP, HMP and HVP (Tables 2-4).

Table 2. Effect of addition of an $84 \mathrm{~g}$ serving of commonly consumed mushrooms (white + crimini + portabella mushrooms at 1:1:1) on energy and nutrients in healthy US-style food pattern (HUP)

\begin{tabular}{|c|c|c|c|c|c|c|}
\hline \multirow[t]{2}{*}{ Variables } & \multicolumn{2}{|c|}{ I,600 kcal HUP } & \multicolumn{2}{|c|}{ 2,000 kcal HUP } & \multicolumn{2}{|c|}{ 2,400 kcal HUP } \\
\hline & Baseline & + Mushroom & Baseline & + Mushroom & Baseline & + Mushroom \\
\hline Energy (kcal) & 1,594 & 1,612 & 2,003 & 2,021 & 2,400 & 2,418 \\
\hline Protein $(\mathrm{g})$ & 83 & 85.2 & 91 & 93.2 & 106 & 108 \\
\hline Carbohydrate (g) & 201 & 204 & 256 & 259 & 310 & 313 \\
\hline Dietary fiber (g) & 25 & 25.8 & 31 & 31.8 & 37 & 37.8 \\
\hline Total fat (g) & 55 & 55.2 & 72 & 72.2 & 87 & 87 \\
\hline Saturated fat (g) & 13.1 & 13.1 & 18.7 & 18.7 & 22.6 & 22.6 \\
\hline Cholesterol (mg) & 190 & 190 & 215 & 215 & 251 & 251 \\
\hline Calcium (mg) & 1,215 & 1,222 & 1,274 & $|, 28|$ & I,377 & $\mathrm{I}, 384$ \\
\hline Copper (mg) & 1.2 & $|.5|^{*}$ & 1.4 & I.7I* & 1.7 & $2.01 *$ \\
\hline Iron (mg) & 14 & 14.3 & 17 & 17.3 & 21 & 21.3 \\
\hline Manganese (mg) & 4 & 4.07 & 4 & 4.07 & 5 & 5.07 \\
\hline Phosphorus (mg) & $\mathrm{I}, 585$ & 1,673 & I,7I7 & 1,805 & 1,964 & 2,052 \\
\hline Potassium (mg) & 2,863 & $3,179 *$ & 3,348 & 3,664 & 3,798 & 4,114 \\
\hline Selenium $(\mu g)$ & 99 & $114 *$ & 110 & $125^{*}$ & 132 & $147^{*}$ \\
\hline Sodium (mg) & 1,602 & 1,608 & I,787 & 1,793 & 2,089 & 2,095 \\
\hline Zinc (mg) & 13 & 13.6 & 14 & 14.6 & 17 & 17.6 \\
\hline Vitamin A, RAE ( $\mu \mathrm{g})$ & 793 & 793 & 898 & 898 & 1,023 & 1,023 \\
\hline Thiamin (mg) & 1.5 & 1.57 & 1.7 & 1.77 & 2.1 & 2.17 \\
\hline Riboflavin (mg) & 1.9 & $2.19 *$ & 2.1 & $2.39 *$ & 2.4 & $2.69 *$ \\
\hline Niacin (mg) & 20 & $23.3^{*}$ & 24 & $27.3^{*}$ & 29 & $32.3^{*}$ \\
\hline Folate, DFE $(\mu \mathrm{g})$ & 491 & 511 & 586 & 606 & 746 & 766 \\
\hline Vitamin $B_{6}(m g)$ & 2 & 2.10 & 2.3 & 2.40 & 2.8 & 2.90 \\
\hline Vitamin $B_{12}(\mu g)$ & 6.5 & 6.55 & 6.8 & 6.85 & 7.8 & 7.85 \\
\hline Vitamin C (mg) & 92 & 92.6 & 117 & 118 & 128 & 129 \\
\hline Vitamin D (IU) & 267 & 273 & 274 & 280 & 295 & 301 \\
\hline Vitamin E (mg) & 8.2 & 8.21 & 10.2 & 10.2 & 12 & 12.0 \\
\hline Choline (mg) & 311 & 328 & 349 & 366 & 402 & 419 \\
\hline
\end{tabular}

Nutrient data on mushrooms was used from Table I. One serving $(84 \mathrm{~g})$ of mushrooms were added to all energy levels. * $10 \%$ or more increase from baseline.

RAE, retinol activity equivalents; DFE, dietary folate equivalents; IU, international units. 
Table 3. Effect of addition of an $84 \mathrm{~g}$ serving of commonly consumed mushrooms (white + crimini + portabella mushrooms at 1:1:1) on energy and nutrients in healthy Mediterranean-style pattern (HMP)

\begin{tabular}{|c|c|c|c|c|c|c|}
\hline \multirow[t]{2}{*}{ Variables } & \multicolumn{2}{|c|}{$\mathrm{I}, 600 \mathrm{kcal} \mathrm{HMP}$} & \multicolumn{2}{|c|}{$2,000 \mathrm{kcal} \mathrm{HMP}$} & \multicolumn{2}{|c|}{ 2,400 kcal HMP } \\
\hline & Baseline & + Mushroom & Baseline & + Mushroom & Baseline & + Mushroom \\
\hline Energy (kcal) & 1,595 & 1,613 & 1,998 & 2,016 & 2,399 & 2,417 \\
\hline Protein $(\mathrm{g})$ & 77 & 79.2 & 89 & 91 & 108 & 110 \\
\hline Carbohydrate (g) & 199 & 202 & 259 & 262 & 313 & 316 \\
\hline Dietary fiber (g) & 25 & 25.8 & 31 & 32 & 38 & 39 \\
\hline Total fat (g) & 58 & 58.2 & 72 & 72 & 85 & 85 \\
\hline Saturated fat (g) & 14.3 & 14.3 & 18 & 18 & 21.4 & 21.4 \\
\hline Cholesterol (mg) & 198 & 198 & 232 & 232 & 268 & 268 \\
\hline Calcium (mg) & 926 & 933 & $\mathrm{I}, 00 \mathrm{I}$ & I,008 & 1,250 & 1,257 \\
\hline Copper (mg) & 1.17 & $1.48^{*}$ & 1.46 & I.77* & 1.74 & $2.05^{*}$ \\
\hline Iron (mg) & 14 & 14.3 & 17 & 17.3 & 22 & 22.3 \\
\hline Manganese (mg) & 4 & 4.07 & 4 & 4.07 & 5 & 5.07 \\
\hline Phosphorus (mg) & I,387 & I,475 & I,572 & 1,660 & 1,929 & 2,017 \\
\hline Potassium (mg) & 2,667 & $2,983^{*}$ & 3,353 & 3,669 & 3,916 & 4,232 \\
\hline Selenium $(\mu \mathrm{g})$ & 99 & $114 *$ & 118 & $133^{*}$ & 143 & $158^{*}$ \\
\hline Sodium (mg) & ।,455 & $|, 46|$ & 1,685 & $|, 69|$ & 2,078 & 2,084 \\
\hline Zinc (mg) & 12 & 12.6 & 14 & 14.6 & 17 & 17.6 \\
\hline Vitamin A, RAE $(\mu \mathrm{g})$ & 705 & 705 & 815 & 815 & 985 & 985 \\
\hline Thiamin (mg) & 1.4 & $\mathrm{I} .47$ & 1.7 & 1.8 & 2.2 & 2.27 \\
\hline Riboflavin (mg) & 1.6 & $1.89 *$ & 1.9 & $2.2^{*}$ & 2.3 & $2.59 *$ \\
\hline Niacin (mg) & 21 & $24.3^{*}$ & 25 & $28.3^{*}$ & 30 & $33.3^{*}$ \\
\hline Folate, DFE $(\mu \mathrm{g})$ & 484 & 504 & 592 & 612 & 757 & 777 \\
\hline Vitamin $B_{6}(m g)$ & 2 & 2.10 & 2.4 & 2.50 & 2.9 & 3.00 \\
\hline Vitamin $B_{12}(\mu g)$ & 6.3 & 6.35 & 7.4 & 7.45 & 8.7 & 8.75 \\
\hline Vitamin C (mg) & 92 & 93 & 134 & 135 & 145 & 146 \\
\hline Vitamin D (IU) & 225 & 231 & 251 & 257 & 299 & 305 \\
\hline Vitamin E (mg) & 8.4 & 8.41 & 10.5 & 10.5 & 12.2 & 12.2 \\
\hline Choline (mg) & 295 & 312 & 345 & 362 & 409 & 426 \\
\hline
\end{tabular}

Nutrient data on mushrooms was used from Table I. One serving $(84 \mathrm{~g})$ of mushrooms were added to all energy levels. * $10 \%$ or more increase from baseline.

RAE, retinol activity equivalents; DFE, dietary folate equivalents; IU, international units.

Addition of an $84 \mathrm{~g}$ serving of mushrooms exposed to UV light to increase vitamin D levels to $200 \mathrm{IU} /$ serving also increased vitamin D by $74.9,73.0$ and $67.8 \%$ in $1,600,2,000$ and 2,400 versions of kcal HUP; by $88.9,79.7$ and $66.9 \%$ in $1,600,2,000$ and 2,400 kcal versions of HMP and by 90.5 , 89.7 and $86.2 \%$ in $1,600,2,000$ and 2,400 kcal versions of HVP (Table 5). Vitamin D was also increased by $9.12,8.89$ and $8.26 \%$ in $1,600,2,000$ and $2,400 \mathrm{kcal}$ versions of HUP; by $10.8,9.7$ and $8.15 \%$ in $1,600,2,000$ and 2,400 kcal versions of HMP and by 11.0, 10.9 and $10.5 \%$ in 1,600, 2,000 and 2,400 kcal versions of HVP by the addition of one serving of oyster mushrooms. Addition of oyster mushroom to USDA Food Patterns also increased choline by 13.2, 11.7 and $10.2 \%$ in 1,600, 2,000 and 2,400 kcal versions of HUP; by $13.9,11.9$ and $10.0 \%$ in $1,600,2,000$ and 2,400 kcal versions of HMP and by 16.2, 14.5 and $13.1 \%$ in 1,600, 2,000 and 2,400 kcal versions of HVP (Table 6).

\section{Discussion}

Results of this modeling study show that the addition of a serving of mushroom had beneficial effects on the nutrient profiles of USDA Food Patterns. The amounts of several key micronutrients increased without increase in calories, sodium, saturated fat or cholesterol in 1,600, 2,000 and 2,400 kcal per day HUP, HMP and HVP. To the best of our knowledge, this is the first dietary modeling analysis of all three USDA Food Patterns investigating the effects of adding a serving of mushrooms. 
Table 4. Effect of addition of an $84 \mathrm{~g}$ serving of commonly consumed mushrooms (white + crimini + portabella mushrooms at 1:1:1) on energy and nutrients in healthy vegetarian pattern (HVP)

\begin{tabular}{|c|c|c|c|c|c|c|}
\hline \multirow[t]{2}{*}{ Variables } & \multicolumn{2}{|c|}{ I,600 kcal HVP } & \multicolumn{2}{|c|}{ 2,000 kcal HVP } & \multicolumn{2}{|c|}{ 2,400 kcal HVP } \\
\hline & Baseline & + Mushroom & Baseline & + Mushroom & Baseline & + Mushroom \\
\hline Energy (kcal) & 1,600 & 1,618 & 1,999 & 2,017 & $2,40 \mathrm{I}$ & 2,419 \\
\hline Protein $(\mathrm{g})$ & 62 & 64.2 & 71 & 73.2 & 82 & 84.2 \\
\hline Carbohydrate (g) & 220 & 223 & 274 & 277 & 332 & 335 \\
\hline Dietary fiber $(\mathrm{g})$ & 28 & 28.8 & 35 & 35.8 & 43 & 43.8 \\
\hline Total fat (g) & 57 & 57.2 & 75 & 75.2 & 90 & 90.2 \\
\hline Saturated fat (g) & 14.4 & 14.4 & 18.6 & 18.6 & 22.6 & 22.6 \\
\hline Cholesterol (mg) & 115 & 115 & 120 & 120 & 125 & 125 \\
\hline Calcium (mg) & 1,253 & 1,260 & 1,333 & $\mathrm{I}, 340$ & $\mathrm{I}, 443$ & 1,450 \\
\hline Copper (mg) & 1.3 & $1.6 I^{*}$ & 1.6 & $1.91 *$ & 1.9 & $2.21 *$ \\
\hline Iron (mg) & 14 & 14.3 & 17 & 17.3 & 22 & 22.3 \\
\hline Manganese (mg) & 3.9 & 3.97 & 4.6 & 4.67 & 5.7 & 5.77 \\
\hline Phosphorus (mg) & $\mathrm{I}, 437$ & $\mathrm{I}, 525$ & 1,596 & $\mathrm{I}, 684$ & $\mathrm{I}, 8 \mathrm{I} 5$ & 1,903 \\
\hline Potassium (mg) & 2,751 & $3,067^{*}$ & 3,311 & $3,627^{*}$ & 3,760 & 4,076 \\
\hline Selenium $(\mu \mathrm{g})$ & 67 & $82.1^{*}$ & 76 & $91.1 *$ & 91 & $106 *$ \\
\hline Sodium (mg) & 1,254 & 1,260 & 1,405 & $\mathrm{I}, 4 \mathrm{II}$ & $|, 63|$ & $\mathrm{I}, 637$ \\
\hline Zinc (mg) & 11 & 11.6 & 12 & 12.6 & 14 & 14.6 \\
\hline Vitamin A, RAE $(\mu \mathrm{g})$ & 776 & 776 & 869 & 869 & 984 & 984 \\
\hline Thiamin (mg) & 1.4 & 1.47 & 1.7 & 1.77 & 2.1 & 2.17 \\
\hline Riboflavin (mg) & 1.8 & $2.09 *$ & 2 & $2.29 *$ & 2.2 & $2.49 *$ \\
\hline Niacin (mg) & 13 & $16.3^{*}$ & 16 & $19.3^{*}$ & 20 & $23.3^{*}$ \\
\hline Folate, DFE $(\mu \mathrm{g})$ & 544 & 564 & 667 & 687 & 846 & 866 \\
\hline Vitamin $B_{6}(m g)$ & 1.7 & 1.80 & 2 & 2.10 & 2.3 & 2.40 \\
\hline Vitamin $B_{12}(\mu g)$ & 3.8 & 3.85 & 4 & 4.05 & 4.4 & 4.45 \\
\hline Vitamin C (mg) & 92 & 92.6 & 116 & 117 & 127 & 128 \\
\hline Vitamin D (IU ) & 221 & 227 & 223 & 229 & 232 & 238 \\
\hline Vitamin E (mg) & 8 & 8.01 & 11 & 11.0 & 13 & 13.0 \\
\hline Choline (mg) & 252 & 269 & 283 & 300 & 313 & 330 \\
\hline
\end{tabular}

Nutrient data on mushrooms was used from Table I. One serving $(84 \mathrm{~g})$ of mushrooms were added to all energy levels. * $10 \%$ or more increase from baseline.

RAE, retinol activity equivalents; DFE, dietary folate equivalents; IU, international units.

Table 5. Effect of addition of an $84 \mathrm{~g}$ serving of UV exposed commonly consumed mushrooms (white + crimini + portabella mushrooms at 1:1:1) on vitamin D contents (IU) in USDA Food Patterns

\begin{tabular}{lllcc}
\hline USDA Food Patterns & Scenarios & I,600 kcal & $2,000 \mathrm{kcal}$ & $2,400 \mathrm{kcal}$ \\
\hline Healthy US-style food pattern & Baseline & $267 \mathrm{IU}$ & $274 \mathrm{IU}$ & $295 \mathrm{IU}$ \\
(HUP) & + Mushrooms & $467 \mathrm{IU}$ & $474 \mathrm{IU}$ & $495 \mathrm{IU}$ \\
& $\%$ Increase & $74.9 \%$ & $73.0 \%$ & $67.8 \%$ \\
Healthy Mediterranean-style & Baseline & $225 \mathrm{IU}$ & $25 \mathrm{IIU}$ & $299 \mathrm{IU}$ \\
pattern (HMP) & + Mushrooms & $425 \mathrm{IU}$ & $45 \mathrm{IIU}$ & $499 \mathrm{IU}$ \\
& \% Increase & $88.9 \%$ & $79.7 \%$ & 66.9 \\
Healthy vegetarian & Baseline & $221 \mathrm{IU}$ & $223 \mathrm{IU}$ & $232 \mathrm{IU}$ \\
pattern (HVP) & + Mushrooms & $42 \mathrm{IU}$ & $423 \mathrm{IU}$ & $432 \mathrm{IU}$ \\
& \% Increase & $90.5 \%$ & $89.7 \%$ & $86.2 \%$ \\
\hline
\end{tabular}

Nutrient data on mushrooms was used from Table I.

IU, international units. 
Table 6. Effect of adding an $84 \mathrm{~g}$ serving of oyster mushrooms on vitamin D (IU) and choline (mg) contents in USDA Food Patterns

\begin{tabular}{|c|c|c|c|c|}
\hline \multirow{2}{*}{ USDA Food Patterns } & \multirow{2}{*}{ Scenarios } & $\mathrm{I}, 600 \mathrm{kcal}$ & $2,000 \mathrm{kcal}$ & $2,400 \mathrm{kcal}$ \\
\hline & & \multicolumn{3}{|c|}{ Vitamin D (IU) } \\
\hline \multirow{3}{*}{$\begin{array}{l}\text { Healthy US-style food } \\
\text { pattern (HUP) }\end{array}$} & Baseline & 267 & 274 & 295 \\
\hline & + Mushrooms & 291 & 298 & 319 \\
\hline & $\%$ Increase & $9.12 \%$ & $8.89 \%$ & $8.26 \%$ \\
\hline \multirow{3}{*}{$\begin{array}{l}\text { Healthy Mediterranean-style } \\
\text { pattern (HMP) }\end{array}$} & Baseline & 225 & 251 & 299 \\
\hline & + Mushrooms & 249 & 275 & 323 \\
\hline & $\%$ Increase & $10.8 \%$ & $9.7 \%$ & $8.15 \%$ \\
\hline \multirow{4}{*}{$\begin{array}{l}\text { Healthy vegetarian } \\
\text { pattern (HVP) }\end{array}$} & Baseline & 221 & 223 & 232 \\
\hline & + Mushrooms & 245 & 247 & 256 \\
\hline & $\%$ Increase & $11.0 \%$ & $10.9 \%$ & $10.5 \%$ \\
\hline & & \multicolumn{3}{|c|}{ Choline (mg) } \\
\hline \multirow{3}{*}{$\begin{array}{l}\text { Healthy US-style food } \\
\text { pattern (HUP) }\end{array}$} & Baseline & 311 & 349 & 402 \\
\hline & + Mushrooms & 352 & 390 & 443 \\
\hline & $\%$ Increase & $13.2 \%$ & $11.7 \%$ & $10.2 \%$ \\
\hline \multirow{3}{*}{$\begin{array}{l}\text { Healthy Mediterranean-style } \\
\text { pattern (HMP) }\end{array}$} & Baseline & 295 & 345 & 409 \\
\hline & + Mushrooms & 336 & 386 & 450 \\
\hline & $\%$ Increase & $13.9 \%$ & $11.9 \%$ & $10.0 \%$ \\
\hline \multirow{3}{*}{$\begin{array}{l}\text { Healthy vegetarian } \\
\text { pattern (HVP) }\end{array}$} & Baseline & 252 & 283 & 313 \\
\hline & + Mushrooms & 293 & 324 & 354 \\
\hline & $\%$ Increase & $16.2 \%$ & $14.5 \%$ & $13.1 \%$ \\
\hline
\end{tabular}

Nutrient data on mushrooms was used from Table I.

IU: international units.

Amounts of potassium, selenium, copper, riboflavin and niacin increased with the addition of a serving of mushrooms to HUP, HMP and HVP. Mushrooms are naturally rich sources of micronutrients that are commonly found not only in vegetables but also in other food groups such as grain and meat $(4,8,13)$. Interestingly, addition of a serving of mushrooms to USDA Food Patterns increased potassium by $8-12 \%$ in our modeling analysis. Potassium is an important nutrient involved in maintaining blood pressure and reducing risk of stroke (1). The adequate intake (AI) of potassium is $3,400 \mathrm{mg} / \mathrm{d}$ for adult male and 2,600 mg/d for adult female (14). Current intake of potassium is low and is about $2,937 \mathrm{mg} / \mathrm{d}$ in adult males age 20 +years and 2,324 mg/d in adult females age 20+ years according to NHANES 2017-2018 data (15). Potassium has been termed as a nutrient of public health concern because its low intakes are associated with health concerns (1). The Scientific Report of the 2020 Dietary Guidelines Advisory Committee (2020 DGAC Report) reaffirmed that potassium is currently under-consumed and is of public health concern (16).

Vitamin D is another nutrient currently under-consumed by Americans and has also been identified as 'shortfall nutrients' by the DGA (1) and also in 2020
DGAC Report (16). Current intake of vitamin D is $168 \mathrm{IU} / \mathrm{d}$ which is less than $30 \%$ of the estimated average requirement (EAR) (17). Mushrooms are a natural source of vitamin D precursor ergosterol, which is converted to vitamin $D_{2}$ when exposed to UV light exposure. A preliminary study reported that a $15 \mathrm{~min}$ exposure to natural sunlight could increase vitamin $\mathrm{D}_{2}$ contents of mushrooms by 150 to $>600 \mathrm{IU} / 70 \mathrm{mg}$, or 25 to $>100 \%$ EAR (18). However, time of day/year, geographical location and other factors affect the rate of vitamin $\mathrm{D}_{2}$ accumulation and therefore, for commercial mushrooms a more controlled approach of UV light exposure of fresh mushroom is used to provide a desired amount of vitamin D. In our modeling analysis, addition of a serving of UV light exposed mushrooms resulted in $67-90 \%$ increase in vitamin D contents of USDA Food Patterns. Some common edible varieties of mushrooms are also rich natural sources of vitamin D (19) and interestingly, addition of oyster mushrooms (specialty mushrooms) also increased vitamin D by $8-11 \%$ in USDA Food Patterns. Addition of oyster mushrooms to food patterns also increased choline by $10-16 \%$. Choline is a complex essential nutrient involved in several diverse body functions including brain and nervous system function $(20,21)$. The AI of choline is $550 \mathrm{mg} /$ day for adult males and $425 \mathrm{mg} /$ day for adult 
females (21). Current intake of choline is low and is only about $70 \%$ of the AI $(15,21)$. The recently published 2020 DGAC Report also indicated that Americans under-consume choline (16).

In addition to vitamins and minerals, mushrooms are rich sources of critical bioactive phytonutrients. They are also one of the best dietary sources of novel antioxidants: sulfur containing amino acid ergothioneine and tripeptide glutathione (10,22-24). Different types of mushrooms vary considerably in ergothioneine and glutathione contents, and oyster mushrooms contains significantly more amounts of these sulfur containing antioxidants than commonly consumed mushrooms: white button, crimini or portabella mushrooms $(10,25)$. The USDA Food Patterns as well as USDA FoodData Central do not include analytical data on these novel antioxidants $(2,12)$. The addition of a serving of commonly consumed mushrooms would be expected to add $2.24 \mathrm{mg}$ ergothioneine and $3.53 \mathrm{mg}$ glutathione, while oyster mushrooms would provide $24.0 \mathrm{mg}$ ergothioneine and $12.3 \mathrm{mg}$ glutathione to the food patterns based on published literature values $(10,22)$. However, further research is needed to access bioavailability of these bioactive nutrients.

It is interesting to note that regardless of the dietary pattern, mushrooms contribute virtually no saturated fat, sodium and cholesterol. Mushrooms are naturally low in calories, saturated fat and sodium and are cholesterol free (12). It may be also be important to note that the dominant fatty acid in mushrooms is linoleic acid - a poly unsaturated fatty acid (PUFA) (12). Additionally, mushroom may contain other plant sterols that may potentially be antiatherogenic. However, the impact of different forms of cooking (frying, baking or microwaving) on stability and/or bioavailability of mushroom nutrients needs further research.

In conclusion, the results of this modeling study provide insight into the nutritional benefits of adding mushrooms to the HUP, HMP and HVP at different calorie levels. Addition of mushrooms to USDA Food Patterns increased several micronutrients including shortfall nutrients, and had a minimal or no impact on overall calories, sodium, saturated fat or cholesterol.

\section{Acknowaledgements}

The study and the writing of the manuscript were supported by the Mushroom Council.

\section{Conflict of interest and funding}

SA as Principal of NutriScience LLC performs nutrition science consulting for various food and beverage companies and related entities; and VLF as Senior Vice President of Nutrition Impact, LLC performs consulting and database analyses for various food and beverage companies and related entities.

\section{References}

1. DHHS, USDA. 2015-2020 Dietary Guidelines for Americans. 8th ed. 2015. Available from: http://health.gov/dietaryguidelines/2015/guidelines/ [cited 23 October 2019].

2. USDA, HHS. Scientific report of the 2015 Dietary Guidelines Advisory Committee. 2015. Available from: https://health.gov/ dietaryguidelines/2015-scientific-report/pdfs/scientific-reportof-the-2015-dietary-guidelines-advisory-committee.pdf [cited 23 October 2019].

3. Davidson A. The Oxford companion to food. New York, NY: Oxford University Press; 1999.

4. Feeney MJ, Miller AM, Roupas P. Mushrooms - biologically distinct and nutritionally unique: exploring a 'Third Food Kingdom'. Nutr Today 2014; 49(6): 301-7. doi: 10.1097/NT.00000 00000000063

5. Alexopoulos CJ, Mims CW, Blackwell M. Introductory mycology. New York, NY: John Wiley and Sons; 1996.

6. Weaver C, Marr ET. White vegetables: a forgotten source of nutrients: purdue roundtable executive summary. Adv Nutr 2013; 4: 318S-26S. doi: 10.3945/an.112.003566

7. USDA's MyPlate. Available from: https://ChooseMyPlate.gov [cited 4 October 2004].

8. Feeney MJ, Dwyer J, Hasler-Lewis CM, Milner JA, Noakes M, Rowe S, et al. Mushrooms and health summit proceedings. J Nutr 2014; 144(1): 1128S-36S. doi: 10.3945/jn.114.190728

9. Kalaras MD, Beelman RB, Elias RJ. Effects of postharvest pulsed UV light treatment of white button mushrooms (Agaricus bisporus) on vitamin D2 content and quality attributes. $\mathrm{J}$ Agric Food Chem 2012; 60(1): 220-5. doi: 10.1021/jf203825e

10. Kalaras MD, Richie JP, Calcagnotto A, Beelman RB. Mushrooms: a rich source of the antioxidants ergothioneine and glutathione. Food Chem 2017; 233: 429-33. doi: 10.1016/j. foodchem.2017.04.109

11. O'Neil CE, Nicklas TA, Fulgoni VL III. Mushroom intake is associated with better nutrient intake and diet quality: 2001-2010 National Health and Nutrition Examination Survey. J Nutr Food Sci 2013; 3(5): 229. doi: 10.4172/2155-9600.100022

12. USDA Food Data Central database. Available from: https://fdc. nal.usda.gov/ [cited 23 October 2019].

13. Beelman RB, Kalaras MD, Richie JP. Micronutrients and bioactive compounds in mushrooms - a recipe for healthy aging. Nutr Today 2019; 54(1): 16-22. doi: 10.1097/NT.00000 00000000315

14. Institute of Medicine, Food and Nutrition Board. Dietary reference intakes for sodium and potassium. Washington, DC: National Academy Press; 2019.

15. USDA/ARS. Nutrient intakes from food and beverages: mean amounts consumed per individual, by gender and age, what we eat in America, NHANES 2017-2018. Available from: https:// www.ars.usda.gov/ARSUserFiles/80400530/pdf/1718/Table_1_ NIN_GEN_17.pdf [cited 13 August 2020].

16. Dietary Guidelines Advisory Committee. Scientific report of the 2020 Dietary Guidelines Advisory Committee: advisory report to the Secretary of Agriculture and the Secretary of Health and Human Services. U.S. Department of Agriculture, Agricultural Research Service, Washington, DC; 2020. Available from: https://www.dietaryguidelines.gov/2020-advisory-committee-report [cited 9 September 2020]. 
17. Institute of Medicine, Food and Nutrition Board. Dietary reference intakes for calcium and vitamin D. Washington, DC: National Academy Press; 2010.

18. Phillips KM, Rasor AS. A nutritionally meaningful increase in vitamin $\mathrm{D}$ in retail mushrooms is attainable by exposure to sunlight prior to consumption. J Nutr Food Sci 2013; 3: 236. doi: $10.4172 / 2155-9600.1000236$

19. Teichmann A, Dutta PC, Staas A, Jagerstad M. Sterol and vitamin D2 concentrations in cultivated and wild grown mushrooms: effects of UV irradiation. LWT - Food Sci Technol 2007; 40(5): 815-22. doi: 10.1016/j.lwt.2006.04.003

20. Zeisel SH, Corbin KD. Choline. In: Erdman JW, Macdonald IA, Zeisel SH, eds. Present knowledge in nutrition. 10th ed. Washington, DC: Wiley-Blackwell; 2012, pp. 405-18.

21. Institute of Medicine, Food and Nutrition Board. Dietary Reference intakes: thiamin, riboflavin, niacin, vitamin $\mathrm{B} 6$, folate, vitamin B12, pantothenic acid, biotin, and choline. Washington, DC: National Academy Press; 1998.

22. Dubost NJ, Ou B, Beelman R. Quantification of polyphenols and ergothioneine in cultivated mushrooms and correlation to total antioxidant capacity. Food Chem 2007; 105(2): 727-35. doi: 10.1016/j.foodchem.2007.01.030

23. Halliwell B, Cheah IK, Tang RMY. Ergothioneine - a diet-derived antioxidant with therapeutic potential. FEBS Lett 2018; 592(20): 3357-66. doi: 10.1002/1873-3468.13123

24. Pizzorno J. Glutathione! Integr Med (Encinitas) 2014; 13(1): 8-12.

25. Dubost NJ, Beelman RB, Peterson D, Royse DJ. Identification and quantification of ergothioneine in cultivated mushrooms by liquid chromatography-mass spectroscopy. Int J Med Mushrooms 2006; 8: 215-22. doi: 10.1615/IntJMedMushr.v8.i3.30

\section{*Sanjiv Agarwal}

NutriScience LLC

901 Heatherwood Drive

East Norriton

PA 19403

USA

Email: agarwal47@yahoo.com 